\title{
Long-term prognosis of ascending aortic aneurysm after aortic valve replacement for bicuspid versus tricuspid aortic valve stenosis
}

\author{
Evaldas Girdauskas, MD, ${ }^{\mathrm{a}}$ Kushtrim Disha, $\mathrm{MD},{ }^{\mathrm{a}}$ Michael A. Borger, $\mathrm{MD}, \mathrm{PhD},{ }^{\mathrm{b}}$ and Thomas Kuntze, $\mathrm{MD}^{\mathrm{a}}$
}

\begin{abstract}
Objective: The bicuspid aorta is thought to have a higher risk of progressive dilation after aortic valve replacement with a subsequently increased risk of adverse aortic events. Our aim was to compare the risk of late aortic events after isolated aortic valve replacement surgery for bicuspid versus tricuspid aortic valve stenosis with concomitant mild to moderate dilatation of the proximal aorta.
\end{abstract}

\begin{abstract}
Methods: A total of 325 consecutive patients (60\% males; mean age, $59.5 \pm 10$ years) with aortic valve stenosis and concomitant ascending aortic dilatation of 40 to $50 \mathrm{~mm}$ underwent isolated aortic valve replacement from 1995 through 2000. A total of 153 patients (47\%) were diagnosed with bicuspid aortic valve stenosis (bicuspid aortic valve group), whereas the remaining 172 patients (53\%) had tricuspid aortic valve stenosis (tricuspid aortic valve group). Follow-up (3566 patient-years) was 100\% complete. Adverse aortic events were defined as the need for proximal aortic surgery or the occurrence of aortic dissection/rupture or sudden death during follow-up.
\end{abstract}

Results: Overall survival was $78 \pm 4 \%$ in the bicuspid aortic valve group versus $55 \pm 6 \%$ in the tricuspid aortic valve group $(P=.006)$ at 15 years postoperatively, but age-adjusted survival was not significantly different between groups $(P=.4)$. A total of 5 patients $(3 \%)$ in the bicuspid aortic valve group versus 9 patients $(5 \%)$ in the tricuspid aortic valve group underwent proximal aortic surgery during follow-up. Aortic dissection occurred in 3 patients in the tricuspid aortic valve group and in no bicuspid aortic valve patients. Fifteen-year freedom from adverse aortic events was $93 \pm 3 \%$ in the bicuspid aortic valve group versus $82 \pm 6 \%$ in the tricuspid aortic valve group $(P=.2)$.

Conclusions: Patients with bicuspid and tricuspid aortic valve stenosis with concomitant mild to moderate ascending aortic dilatation are at comparably low risk of adverse aortic events 15 years after isolated aortic valve replacement. (J Thorac Cardiovasc Surg 2014;147:276-82)

The bicuspid aorta has been proposed to dilate progressively after isolated aortic valve replacement (AVR) at an accelerated rate, a process that is followed by an increased risk of adverse aortic events. ${ }^{1,2}$ The explanation for this phenomenon has been based predominantly on the genetic hypothesis of aortopathy in bicuspid aortic valve (BAV) disease. $^{2-4}$ The widespread popularity of the genetic theory, which considers BAV aortopathy a congenital disorder of vascular connective tissue, has led to more aggressive treatment recommendations of the proximal aorta in such patients, approaching aortic management recommendations of Marfan syndrome. ${ }^{5,6}$ However, such an aggressive surgical treatment strategy of BAV aortopathy has been questioned by some investigators. ${ }^{7}$

Recent in vitro and in vivo studies brought major advances in the understanding of BAV function $^{8,9}$ and

From the Department of Cardiac Surgery, ${ }^{\text {a }}$ Central Hospital Bad Berka, Bad Berka, Germany; and the Department of Cardiac Surgery, ${ }^{\mathrm{b}}$ Heart Center Leipzig, Leipzig, Germany.

Disclosures: Authors have nothing to disclose with regard to commercial support. Received for publication Aug 23, 2012; revisions received Oct 5, 2012; accepted for publication Nov 6, 2012; available ahead of print Dec 14, 2012.

Address for reprints: Evaldas Girdauskas, MD, Department of Cardiac Surgery, Central Hospital Bad Berka, R. -Koch -Allee 9, 99437 Bad Berka, Germany (E-mail: evagird@centras.lt).

$0022-5223 / \$ 36.00$

Copyright (C) 2014 by The American Association for Thoracic Surgery

http://dx.doi.org/10.1016/j.jtcvs.2012.11.004 provided hemodynamic insight into the different clinical forms of BAV disease. ${ }^{10,11}$ In the face of these recent important findings, the reevaluation of clinical data on bicuspid aortopathy is appropriate. Considering the heterogeneity of BAV disease, ${ }^{12,13}$ clinical research should also take into account the distinct homogeneous patient subgroups. We therefore restricted our analysis to 1 clinically relevant subgroup of BAV patients-those with bicuspid valve stenosis and mild to moderate dilatation of the proximal aorta who underwent isolated AVR surgery.

Our aim was to compare the risk of late aortic events after isolated AVR for bicuspid versus tricuspid aortic valve stenosis with concomitant mild to moderate dilatation of the proximal aorta using long-term follow-up.

\section{METHODS}

We reviewed our institutional valve surgery database to identify all patients who underwent isolated AVR for predominant/pure aortic valve stenosis with concomitant ascending aortic dilatation of 40 to $50 \mathrm{~mm}$ between January 1995 and January 2001 at the Central Hospital Bad Berka. A total of 1095 patients underwent an isolated AVR surgery during the study period (255 BAV patients and 840 tricuspid aortic valve [TAV] patients). Concomitant replacement of the proximal aorta was required in 110 patients with dilatation of the ascending aorta $>50 \mathrm{~mm}$ (53 BAV patients and 57 TAV patients). Patients with mixed aortic valve lesions were included only if valve stenosis was the predominant lesion (ie, patients with a severe stenosis and mild to moderate aortic valve insufficiency were assigned to 


\section{Abbreviations and Acronyms \\ $\mathrm{AVR}=$ aortic valve replacement \\ $\mathrm{BAV}=$ bicuspid aortic valve \\ $\mathrm{TAV}=$ tricuspid aortic valve}

the stenosis subgroup). Patients who underwent AVR surgery after 2001 were not included to have an adequate long-term follow-up (ie, at least 10 years post-AVR).

A total of 325 consecutive patients with predominant/pure aortic valve stenosis and concomitant ascending aortic dilatation of 40 to $50 \mathrm{~mm}$ underwent isolated AVR surgery during the study period. Patients with bicuspid aortic valve stenosis (BAV group, $\mathrm{n}=153$ ) were identified and compared with those with tricuspid valve stenosis (TAV group, $n=172$ ). The valve was identified as bicuspid or tricuspid based principally on intraoperative direct inspection (discussed later). Study approval was obtained from the local ethics committee. Individual patient consent was waived.

The primary end point of our study was freedom from late adverse aortic events in the BAV group versus the TAV group. Adverse aortic events were defined as the need for proximal aortic surgery or the occurrence of aortic dissection/rupture or sudden cardiac death during longterm follow-up.

\section{Definitions and Measurements}

The morphology and function of the aortic valve was assessed by preoperative echocardiography in all patients. The BAV was suspected if 2-dimensional short-axis imaging of the aortic valve demonstrated the existence of only 2 commissures delimiting 2 aortic valve cusps. The final decision regarding the bicuspidality or tricuspidality of the aortic valve, however, was made based on the intraoperative description of valve morphology by the surgeon. Aortic valve stenosis was defined using the uniform and validated Doppler-based echocardiographic measurements.

The diameter of the proximal aorta was measured preoperatively by means of transthoracic 2-dimensional echocardiography and routine aortic angiography during cardiac catheterization. Multiple echocardiographic measurements of the maximal diameter of the ascending aorta were performed in systole using a parasternal long-axis view. Moreover, proximal aortic dimensions were measured at multiple sites on aortic angiography and the maximal aortic diameter was recorded. A proximal aortic diameter of $40 \mathrm{~mm}$ was our cutoff value for defining dilatation of the aorta. In the current study, we used the maximal diameter of the proximal aorta, which was the supracoronary portion in the vast majority of our study population. Therefore, this measure is restricted mostly to the ascending portion of the proximal aorta. All patients with a dilated proximal aorta, as diagnosed in these screening examinations, underwent subsequent preoperative computed tomography or magnetic resonance angiography of the thoracic aorta. Moreover, the maximal diameter of the proximal aorta was measured routinely intraoperatively (ie, using a caliper) before going on pump. The proximal aorta was defined as normal size only if all 3 measurements (ie, echocardiography, aortic angiography, and intraoperative measurement) described the aortic diameter consistently of $<40 \mathrm{~mm}$. If a proximal aortic aneurysm $>50 \mathrm{~mm}$ in maximal diameter was observed, then simultaneous aortic surgery was performed. In all remaining patients with a proximal aortic diameter of 40 to $50 \mathrm{~mm}$, isolated AVR was performed.

Arterial hypertension was defined as a systemic blood pressure of $>140 /$ $90 \mathrm{~mm} \mathrm{Hg}$ recorded at multiple measurements and/or evidence of longstanding systemic hypertension treated by medication before AVR. Systemic hypertension was treated by medication in $80 \%$ of the study patients.

\section{Study Population}

Demographics and intraoperative variables of both study groups are displayed in Table 1. Patients in the BAV group were significantly younger and less symptomatic compared with the TAV group. Moreover, there was a clear predominance of male patients in the BAV group. More important, no significant difference in the diameter of ascending aorta was found between the study groups at the time of AVR surgery.

All 325 patients underwent conventional isolated AVR surgery through a median sternotomy or partial upper L-ministernotomy using standard cardiopulmonary bypass and moderate systemic hypothermia. Intraoperative management was uniform without any major changes over time. The intraoperative variables of both study groups are presented in Table 2. Aortic crossclamp time and cardiopulmonary bypass time tended to be longer in the BAV group. Moreover, a mechanical valve prosthesis was implanted more frequently in the BAV group compared with the TAV group. There was a tendency toward an implantation of a larger prosthesis size in the $\mathrm{BAV}$ group.

\section{Follow-up}

Our follow-up protocol consisted of a telephone interview with the patients, their family members, and/or the patients' general practitioners. All imaging data obtained during the postoperative course (echocardiography reports, computed tomographic scans/magnetic resonance angiographic images) were obtained from patients' cardiologists or general practitioners and were entered into our database. There was no standard follow-up protocol for aortic imaging in the current study. Surgical notes were obtained on all patients who underwent redo cardiac surgery. A total of 62 patients $(19 \%)$ were treated for noncardiac reasons in our hospital during the postoperative course and their medical records were obtained for follow-up. All medical records of patients who died in external hospitals were forwarded on request to our hospital. In all cases of out-of-hospital death, we aimed to confirm or exclude sudden cardiac death. In a total of 35 patients $(11 \%)$ in whom no contact details were available, a telephone book-based search was performed.

\section{Statistical Analysis}

Standard definitions were used for patient variables and outcomes. Categorical variables are expressed as percentages, and continuous variables are expressed as mean \pm standard deviation with range. All statistical analyses were performed with the IBM SPSS 19.0 software (IBM Corp, New York, NY). Survival analysis was performed according to the methods of Kaplan-Meier, and statistical differences were analyzed using the logrank test. Age-adjusted survival was compared using the log-rank test. A multivariable analysis (ie, Cox regression) of risk factors for adverse aortic events was performed. All variables were screened initially in the univariate model and were considered for clinical relevance before including them in the multivariate model.

\section{RESULTS \\ Perioperative Results}

The in-hospital outcomes are summarized in Table 3. In-hospital mortality was comparable between the study groups (ie, $0.7 \%$ in the BAV group vs $2.3 \%$ in the TAV group, $P=.3$ ). Two patients (1 patient in the BAV group and 1 patient in the TAV group) died suddenly on the surgical ward, most probably as a result of a fatal arrhythmia. An autopsy examination was performed in both cases without evidence of aortic dissection or rupture. One patient in the TAV group died of major stroke 3 days after AVR surgery. Two additional patients in the TAV group 
TABLE 1. Demographics and intraoperative variables

\begin{tabular}{|c|c|c|c|}
\hline Variable & $\begin{array}{l}\text { BAV group } \\
(\mathbf{n}=\mathbf{1 5 3})\end{array}$ & $\begin{array}{l}\text { TAV group } \\
(\mathbf{n}=\mathbf{1 7 2})\end{array}$ & $\begin{array}{c}P \\
\text { value }\end{array}$ \\
\hline $\begin{array}{l}\text { Mean age, } y ; \\
\text { mean } \pm \mathrm{SD} \text { (range) }\end{array}$ & $54 \pm 11(22-76)$ & $64 \pm 7(42-75)$ & $<.00$ \\
\hline Male, n (\%) & $112(73)$ & $82(48)$ & $<.00$ \\
\hline $\begin{array}{l}\mathrm{BSA}, \mathrm{m}^{2} ; \\
\quad \text { mean } \pm \mathrm{SD} \text { (range) }\end{array}$ & $1.7 \pm 0.2(1.3-2.2)$ & $1.7 \pm 0.2(1.4-2.3)$ & .7 \\
\hline $\begin{array}{l}\text { NYHA class III/IV, } \\
\text { n }(\%)\end{array}$ & $77(50)$ & $107(62)$ & .03 \\
\hline $\begin{array}{l}\text { Ascending aorta, } \mathrm{mm} ; \\
\text { mean } \pm \mathrm{SD} \text { (range)* }\end{array}$ & $46 \pm 3(40-50)$ & $45 \pm 4(40-50)$ & .5 \\
\hline $\begin{array}{l}\text { Ascending aorta } \\
\quad \geq 45 \mathrm{~mm}, \mathrm{n}(\%)^{*}\end{array}$ & $60(39)$ & $70(40)$ & .9 \\
\hline $\begin{array}{l}\text { Arterial hypertension, } \\
\mathrm{n}(\%)\end{array}$ & $74(48)$ & $98(57)$ & .2 \\
\hline Diabetes, $\mathrm{n}(\%)$ & $17(11)$ & $27(16)$ & .6 \\
\hline $\begin{array}{l}\text { History of smoking, } \\
\mathrm{n}(\%)\end{array}$ & $55(36)$ & $69(40)$ & .6 \\
\hline $\begin{array}{l}\text { Peripheral arterial } \\
\text { disease, } \mathrm{n}(\%)\end{array}$ & $4(3)$ & $5(3)$ & .9 \\
\hline COLD, n $(\%)$ & $14(9)$ & $15(9)$ & .9 \\
\hline $\begin{array}{l}\text { Urgent/emergency } \\
\text { surgery, } \mathrm{n}(\%)\end{array}$ & $19(12)$ & $27(16)$ & .4 \\
\hline $\begin{array}{l}\mathrm{CPB} \text { time, } \mathrm{min} ; \\
\text { mean } \pm \mathrm{SD}(\text { range })\end{array}$ & $73 \pm 21(45-190)$ & $69 \pm 16(47-141)$ & .06 \\
\hline $\begin{array}{l}\text { Crossclamp time, min; } \\
\text { mean } \pm \text { SD (range) }\end{array}$ & $37 \pm 10(31-71)$ & $35 \pm 8(30-60)$ & .1 \\
\hline Mechanical prosthesis & $142(93)$ & $146(85)$ & .05 \\
\hline $\begin{array}{l}\text { Mean prosthesis } \\
\text { size, } \mathrm{mm} \text {; } \\
\text { mean } \pm \mathrm{SD} \text { (range) }\end{array}$ & $25 \pm 2(21-29)$ & $24 \pm 2(21-29)$ & .07 \\
\hline
\end{tabular}

$B A V$, Bicuspid aortic valve; $T A V$, tricuspid aortic valve; $S D$, standard deviation; $B S A$, body surface area; NYHA, New York Heart Association; COLD, chronic obstructive lung disease; $C P B$, cardiopulmonary bypass. *As measured by preoperative computed tomography/magnetic resonance angiography.

succumbed during a complicated, prolonged in-hospital course (ie, resulting from sepsis-induced multiorgan failure in 1 patient and multiple bleeding complications in the other). None of the in-hospital deaths were aortic related.

TABLE 2. In-hospital outcomes

\begin{tabular}{lccc}
\hline \multicolumn{1}{c}{ Variable } & $\begin{array}{c}\text { BAV group } \\
(\mathbf{n}=\mathbf{1 5 3})\end{array}$ & $\begin{array}{c}\text { TAV group } \\
(\mathbf{n}=\mathbf{1 7 2})\end{array}$ & $\begin{array}{c}\boldsymbol{P} \\
\text { value }\end{array}$ \\
\hline $\begin{array}{l}\text { Low-cardiac output syndrome, } \\
\text { n (\%) }\end{array}$ & $4(3)$ & $8(5)$ & .8 \\
Reoperation for bleeding, n (\%) & $7(5)$ & $17(10)$ & .1 \\
$\begin{array}{l}\text { Dialysis-dependant renal } \\
\text { failure, n (\%) }\end{array}$ & $1(1)$ & $2(1)$ & .9 \\
Stroke, n (\%) & $2(1)$ & $4(2)$ & .5 \\
Tracheotomy, n (\%) & $2(1)$ & $5(3)$ & .8 \\
Hospital stay, days, & $14 \pm 7(8-59)$ & $15 \pm 8(2-74)$ & .3 \\
$\quad$ mean \pm SD (range) & & & \\
Hospital mortality, n (\%) & $1(0.7)$ & $4(2.3)$ & .3 \\
\hline
\end{tabular}

$B A V$, Bicuspid aortic valve; $T A V$, tricuspid aortic valve; $S D$, standard deviation.
TABLE 3. Causes of late deaths

\begin{tabular}{lcc}
\hline \multicolumn{1}{c}{ Cause of death } & $\begin{array}{c}\text { BAV group, } \\
\text { n }(\mathbf{n}=\mathbf{1 5 2})\end{array}$ & $\begin{array}{c}\text { TAV group, } \\
\mathbf{n}(\mathbf{n}=\mathbf{1 6 8})\end{array}$ \\
\hline Cardiac death & $15(57 \%)$ & $21(45 \%)$ \\
Congestive heart failure & 2 & 3 \\
Myocardial infarction & 2 & 1 \\
Aortic dissection & 0 & 2 \\
Arrhythmia & 0 & 1 \\
Valve related & & \\
Stroke & 4 & 4 \\
Hemorrhage & 3 & 2 \\
Thrombosis & 0 & 1 \\
$\quad$ Endocarditis & 1 & 1 \\
Sudden death & 3 & 6 \\
Noncardiac death & $12(43 \%)$ & $23(49 \%)$ \\
Malignancy & 4 & 14 \\
Chronic end-stage disease & 3 & 6 \\
Infection & 3 & 3 \\
Trauma & 1 & 0 \\
Suicide & 1 & 0 \\
Unknown & 0 & $3(6 \%)$ \\
Total death & 27 & 47 \\
\hline BAV, Bith
\end{tabular}

$B A V$, Bicuspid aortic valve; $T A V$, tricuspid aortic valve

\section{Follow-up Results}

Follow-up data (a total of 3566 patient-years) were obtained on all 320 hospital survivors $(100 \%)$. The mean length of follow was of comparable duration between groups-11.5 \pm 3.2 years in the BAV group versus 10.5 \pm 6 years in the TAV group $(P=.1)$.

A total of 27 patients $(18 \%)$ in the BAV group versus 47 patients $(28 \%)$ in the TAV group died during follow-up. The causes of late deaths in both groups are summarized in Table 3. The causes of late deaths were mostly cardiac related $(57 \%)$ in the BAV group, and 3 of these patients died suddenly. Cardiac and noncardiac causes were almost equally distributed in the TAV group, and the largest proportion of TAV patients died of malignancies ( $\mathrm{n}=14$ patients). More important, 6 patients in the TAV group and 3 patients in the BAV group experienced sudden cardiac death. Moreover, 2 patients in the TAV group died of chronic type A aortic dissection after redo surgery.

The overall survival after the 15-year follow-up was $78 \pm$ $4 \%$ in the BAV group versus $55 \pm 6 \%$ in the TAV group (log rank, $P=.006$; Figure 1 ). We also performed an age-adjusted survival analysis because of the markedly different ages of the 2 groups at baseline. We failed to find a significant difference in age-adjusted survival $(P=.4)$.

\section{Proximal Aortic Surgery}

Proximal aortic surgery was required in 5 patients $(3 \%)$ in the BAV group versus 9 patients $(5 \%)$ in the TAV group. The prevalence of proximal aortic surgery was 2.8 of 1000 patient-years in the BAV group versus 5.0 of 1000 patient-years in the TAV group. The mean length of time 


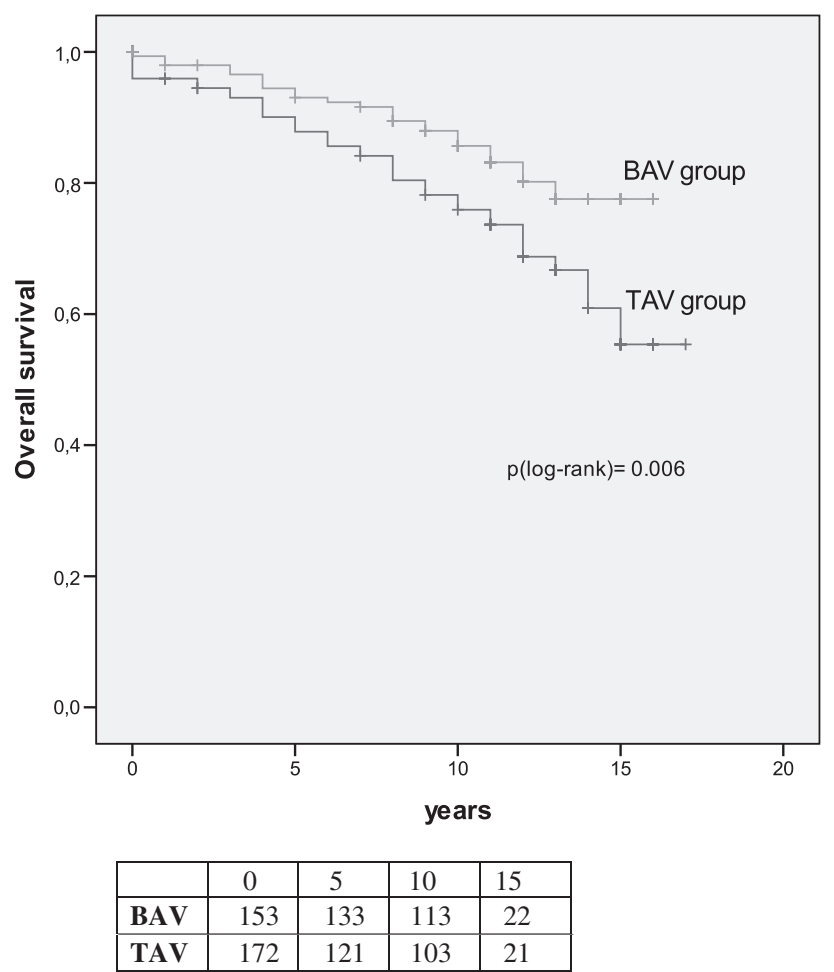

FIGURE 1. Overall survival (Kaplan-Meier). $B A V$, Bicuspid aortic valve; $T A V$, tricuspid aortic valve.

between AVR and proximal aortic surgery was comparable between the groups (ie, $8 \pm 2$ years in the BAV group vs $9 \pm$ 4 years in the TAV group, $P=.3$ ). The freedom from proximal aortic surgery at 15 years post-AVR was $94 \pm 3 \%$ in the BAV group versus $89 \pm 5 \%$ in the TAV group (log rank, $P=.2$ ).

The most common indication for proximal aortic surgery was progression of the ascending aortic aneurysm. More important, 3 patients in the TAV group required urgent/emergency aortic surgery for type A aortic dissection (ie, 2 chronic and 1 acute aortic dissection), whereas no cases of aortic dissection were observed in the BAV group. The mean diameter of the proximal aorta at the time of aortic surgery was $53 \pm 2 \mathrm{~mm}$ in the BAV group versus $67 \pm 15 \mathrm{~mm}$ in the TAV group $(P=.005)$. This difference was predominantly a result of the markedly dilated diameters of the proximal aorta in 3 patients with aortic dissections in the TAV group (ie, diameters of the proximal aorta of $110 \mathrm{~mm}, 75$ $\mathrm{mm}$, and $80 \mathrm{~mm}$, respectively). The surgical treatment strategy of the proximal aorta was comparable between the groups; a composite graft aortic root replacement was performed in the majority of patients (ie, $60 \%$ in both groups). The remaining reoperated patients underwent supracoronary replacement of the ascending aorta and replacement of the mechanical valve with a bioprosthesis.

Additional indications for redo surgery without intervention on the aorta were observed in 2 patients in the BAV group and in 1 patient in the TAV group. One such patient

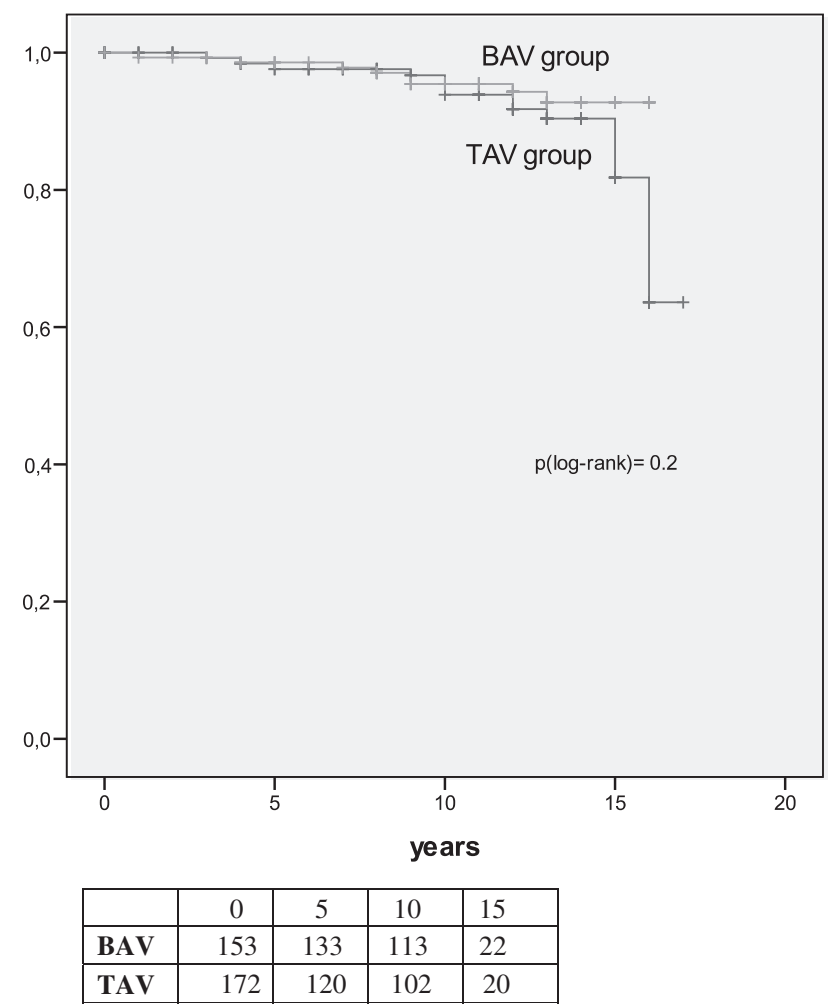

FIGURE 2. Freedom from adverse aortic events (Kaplan-Meier). $B A V$, Bicuspid aortic valve; $T A V$, tricuspid aortic valve.

in the BAV group had multiple bleeding events resulting from oral anticoagulation and required a biological prosthesis. The second patient had a significant paravalvular leak with accompanying hemolysis, requiring redo AVR. One patient in the TAV group underwent subsequent coronary artery bypass grafting because of symptomatic 3-vessel coronary artery disease.

All 5 patients in the BAV group survived the redo surgery uneventfully, whereas 2 patients in the TAV group (with type A aortic dissection) expired postoperatively. One patient died of low cardiac output on the second postoperative day. The second patient experienced a severe systemic inflammatory response syndrome immediately after surgery and died of progressive multiorgan failure within the first 6 hours after operation.

The primary end point variable (ie, adverse aortic events) occurred in 8 of 152 patients $(5 \%)$ in the BAV group versus 15 of 168 patients $(9 \%)$ in the TAV group. The freedom from adverse aortic events at 15 years post-AVR was 93 $\pm 3 \%$ in the BAV group versus $82 \pm 6 \%$ in the TAV group (log rank, $P=.2$; Figure 2).

A Cox regression analysis was performed to identify independent risk factors of adverse aortic events. A total of 3 variables were included in the multivariate model—namely, the presence of $\mathrm{BAV}$, proximal aortic diameter at the time of AVR surgery (as a continuous variable), and arterial 
TABLE 4. Risk factors of adverse aortic events (Cox regression)

\begin{tabular}{lclc}
\hline \multicolumn{1}{c}{ Variable } & Hazard ratio & $\mathbf{9 5} \% \mathbf{C I}$ & $\boldsymbol{P}$ value \\
\hline Hypertension & 4.8 & $1.2-22.4$ & .04 \\
Ascending aorta, $\mathrm{mm}^{*}$ & 1.3 & $0.3-3.9$ & .8 \\
BAV disease & 0.8 & $0.4-2.7$ & .8 \\
\hline
\end{tabular}

$C I$, Confidence interval; $B A V$, bicuspid aortic valve. $*$ In the range of 40 to $50 \mathrm{~mm}$, as defined by preoperative computed tomography/magnetic resonance angiography.

hypertension (Table 4). Arterial hypertension was identified as a significant predictor of adverse aortic events (hazard ratio, 4.8; 95\% confidence interval, 1.2-22.4).

\section{DISCUSSION}

The treatment of dilated proximal aorta in patients with BAV disease is controversial. ${ }^{14}$ The increased risk of acute aortic complications has been proposed in BAV patients, including a 9-fold higher prevalence of aortic dissection in some series. ${ }^{15,16}$ Most of these data come from large necropsy studies, however, which may inherently overestimate the prevalence of aortic complications in the BAV population. Larger dimensions of the proximal aorta in persons with BAV versus TAV have been presumed to result in an increased risk of acute aortic complications during follow-up. However, direct evidence of an increased risk of adverse aortic events in such patients is lacking. Observed dilatation of the proximal aorta without echocardiographic criteria of relevant BAV stenosis or insufficiency (ie, aortic dilatation out of proportion to coexistent valvular lesion) has also served as a strong argument for the congenital origin of BAV aortopathy, ${ }^{17}$ further supporting the argument for a more aggressive approach to aortic management in such patients.

Since the pioneering contribution by Robicsek and colleagues, ${ }^{18}$ an ever-increasing amount of clinical and basic science studies have focused on the function of "clinically normal" BAV and the patterns of transvalvular flow. ${ }^{8-11}$ These studies showed consistently eccentric turbulent transvalvular flow in the setting of the clinically normal BAV. ${ }^{8,9}$ Moreover, a strong correlation has been demonstrated between the specific transvalvular flow pattern and the segmental dilatation of the proximal aorta in BAV disease. ${ }^{10,11}$ Another important study compared biomolecular changes in the ascending aorta of patients with bicuspid versus tricuspid aortic valve stenosis at the time of AVR surgery. ${ }^{19}$ Bicuspid aortic valve stenosis was associated with a more severe medial remodeling of the ascending aorta, which occurred earlier during the aneurysm course, and it had an asymmetric spatial pattern compared with that observed with TAV stenosis. These findings confirm once again the more severe transvalvular flow disturbances in BAV patients and add more support to the hemodynamic theory, as opposed to the genetic theory, of BAV-associated aortopathy.

Based on these important recent in vitro and in vivo findings, we addressed the issue of pathogenesis of BAV aortopathy in a systematic review of the literature. ${ }^{20}$ One of the key questions in this review was the natural course of the proximal aorta in BAV patients after isolated AVR. The cumulative analysis of results from 3 follow-up studies $^{2,21,22}$ showed that about 5 to $30 \%$ of BAV patients may experience late aortic events after isolated AVR surgery. However, the majority of these events were replacement of the aorta during planned, elective redo AVR surgery. The incidence of documented catastrophic acute aortic events (ie, aortic dissection or rupture) was considerably lowonly 6 events in 5288 cumulative patient-years. Because of the high variability in the prevalence of aortic events among these studies (ie, heterogeneous characteristics of the included patients), no definite conclusions could be drawn.

Recently, a very low risk of late aortic events (ie, 1.9\% risk of cumulative events after median follow-up of 12 years) has been demonstrated in a BAV cohort after isolated AVR surgery in a large-scale follow-up study from the Mayo Clinic. ${ }^{23}$ Our current study confirms this considerably low risk of adverse aortic events in the BAV group (ie, 93\% freedom from adverse aortic events at 15 years post-AVR).

One important difference between our study and that of the Mayo Clinic, however, is that our BAV group consisted of a homogeneous (and most common) phenotype of BAV disease (ie, BAV stenosis with concomitant mild to moderate ascending aortic dilatation). The risk of adverse aortic events may be higher in the subgroup of BAV patients with isolated aortic valve insufficiency and dilatation of aortic root (ie, root dilatation phenotype). ${ }^{20}$ This heterogeneity of the BAV population may explain the extraordinary high rate of aortic events in some previously published follow-up studies. ${ }^{2}$

Progressive dilatation of the ascending aorta after isolated AVR surgery in BAV patients compared with TAV patients has been advocated in 1 previously published study. ${ }^{1}$ However, the conclusions in that report were based on retrospectively analyzed data on $13 \mathrm{BAV}$ patients versus $14 \mathrm{TAV}$ patients. Moreover, only 5 patients in the bicuspid subgroup had a predominant BAV stenosis. Therefore, the findings of this study may not be generalized to the entire BAV population.

In the current study, we found a comparably low risk of adverse aortic events 15 years after isolated AVR in patients with BAV versus TAV stenosis and concomitant mild to moderate dilatation of the ascending aorta. No difference was found in the prevalence of proximal aortic surgery between the study groups. Interestingly, 3 patients in the TAV group underwent proximal aortic surgery for type A aortic dissection. In contrast, no documented aortic dissection occurred in the BAV group. These findings support our previous assumption that mildly to moderately dilated ascending aorta in BAV stenosis behaves similar to the ascending aorta of comparable dimensions in TAV stenosis during longterm follow-up after isolated AVR surgery.

To the best of our knowledge, this is the first published report that compares the risk of late aortic events after isolated 
AVR for BAV versus TAV stenosis and concomitant mild to moderate dilatation of the ascending aorta. Andrus and associate $^{24}$ analyzed the natural course of ascending aortic aneurysms after isolated AVR by means of echocardiographic follow-up. However, only half of their patients had a baseline ascending aorta diameter $\geq 35 \mathrm{~mm}$ and only $13 \%$ had a congenital lesion of the aortic valve (ie, mono- and bicuspid valves). Moreover, that study did not differentiate between aortic valve stenosis and insufficiency. The authors found no significant clinical or valvular characteristics that predicted progressive dilatation of the ascending aorta. Moreover, 2 additional studies analyzed the natural history of ascending aortic aneurysms in the setting of unreplaced BAV and compared them with the TAV population. ${ }^{25,26}$ Surprisingly, both of these studies demonstrated similar rates of adverse aortic events in the BAV versus the TAV groups. Moreover, the study by Davies and coworkers ${ }^{26}$ found a significant correlation between adverse aortic events and the presence of relevant aortic stenosis.

In accordance with a previously published study, ${ }^{27}$ we identified arterial hypertension as the only significant predictor of adverse aortic events after isolated AVR for aortic valve stenosis. In particular, bicuspid valve pathology was not a predictor of long-term aortic events.

We are aware of the fact, that the supracoronary ascending aortic replacement does not add much to AVR surgery and does not really increase surgical risk in experienced hands. Long-term benefit in terms of protection from proximal aortic complications is obvious. However, this additional surgical maneuver may be associated with an increased risk of bleeding events and transfusion requirements, especially in patients receiving anticoagulation/antiplatelet medication. In addition, we have all seen rare but dramatic complications from a supracoronary aortic replacement. Moreover, the complexity of subsequent redo surgery, which may be quite common in the relatively young BAV population, may be significantly increased after simultaneous aortic surgery. Nowadays, many isolated AVR operations are performed using minimally invasive approaches, and the simultaneous proximal aortic surgery may increase the complexity of such procedures. Last, we believe that our data-in combination with several lines of evidence from other studies suggesting a more benign course for BAV aortopathy-is important to counter the increasingly aggressive approach to BAV-associated aortopathy that has led some centers to replace such aortas routinely starting at a diameter of $4.0 \mathrm{~cm}$.

\section{Study Limitations}

The current study is a retrospective analysis with all known limitations of such a study design. There are some inherent age and comorbidity-related differences between the study groups, which limit their comparability in part. Patients with the degenerative TAV stenosis are generally older and sicker compared with the BAV population, resulting in decreased long-term survival and a higher prevalence of late noncardiac deaths. Therefore, age-adjusted comparisons were performed using an analysis of covariance.

A proximal aortic diameter of $40 \mathrm{~mm}$ was our uniform cutoff value for defining the dilatation of the aorta throughout the years of the study. However, this is an arbitrary value that may represent a limitation of our study.

Moreover, the relative aortic size compared with the aortic isthmus was not available in the current study. We corrected the proximal aortic size for body surface area only, which was comparable between the study groups.

The use of a composite end point that includes elective proximal aortic surgery may be potentially misleading, because it may be influenced by the personal experience and the expertise of the surgical team toward the criteria of replacement of a dilated aorta. However, redo aortic surgery is a major event during the postoperative course after AVR, and it has been included in a combined end point for the majority of prior follow-up studies.

Last, we were not able to define the exact progression rate of proximal aortic diameter in both study groups during follow-up. Serial aortic imaging (ie, computed tomography or magnetic resonance angiography) was available in only 65 of 320 patients $(20 \%)$ in the study population. Therefore, we decided not to include the aortic growth rate, based on this small proportion of the study population. Given the relatively modest progression rate of proximal aortic diameter in patients who underwent redo aortic surgery (with the only exception of 3 patients with aortic dissection) and the low total number of adverse aortic events, it may be hypothesized that the progression rate of proximal aortic dimensions in the remaining study population was most probably modest.

\section{CONCLUSIONS}

Our study demonstrates that patients with BAV versus TAV stenosis and concomitant mild to moderate ascending aortic dilatation are at comparably low risk of adverse aortic events 15 years after isolated AVR. Based on these findings, a conservative treatment strategy of the ascending aorta at the time of AVR surgery in patients with aortic valve stenosis is warranted. However, caution should be advised when one generalizes these results to patients with BAV insufficiency or other risk factors for aortic dilation. Moreover, a thorough aortic imaging follow-up is required to determine the rate of aortic growth in patients with BAV versus TAV stenosis and concomitant mild to moderate ascending aortic dilatation after isolated AVR.

\section{References}

1. Yasuda H, Nakatani S, Stugaard M, Tsujita-Kuroda Y, Bando K, Kobayashi J, et al. Failure to prevent progressive dilation of ascending aorta by aortic valve replacement in patients with bicuspid aortic valve: comparison with tricuspid aortic valve. Circulation. 2003;108:II-291-4. 
2. Russo CF, Mazzetti S, Garatti A, Ribera E, Milazzo A, Bruschi G, et al. Aortic complications after bicuspid aortic valve replacement: long-term results. Ann Thorac Surg. 2002;74:S1773-6.

3. Silberbach M. Bicuspid aortic valve and thoracic aortic aneurysm: toward a unified theory. J Am Coll Cardiol. 2009;53:2296-7.

4. Friedman T, Mani A, Elefteriades JA. Bicuspid aortic valve: clinical approach and scientific review of a common clinical entity. Expert Rev Cardiovasc Ther. 2008;6:235-48.

5. Etz CD, Homann TM, Silovitz D, Spielvogel D, Bodian CA, Luehr M, et al. Long-term survival after the Bentall procedure in 206 patients with bicuspid aortic valve. Ann Thorac Surg. 2007;84:1186-94.

6. Fazel SS, Mallidi HR, Lee RS, Sheehan MP, Liang D, Fleischmann D, et al. The aortopathy of bicuspid aortic valve disease has distinctive patterns and usually involves the transverse aortic arch. J Thorac Cardiovasc Surg. 2008;135:901-7.

7. Guntheroth WG. A critical review of the ACC/AHA practice guidelines on bicuspid aortic valve with dilated ascending aorta. Am J Cardiol. 2008;102:107-10.

8. Conti CA, Della Corte A, Votta E, Del Viscovo L, Bancone C, De Santo LS, et al. Biomechanical implications of the congenital bicuspid aortic valve: a finite element study of aortic root function from in vivo data. J Thorac Cardiovasc Surg. 2010;140:890-6.

9. Saikrishnan N, Yap CH, Milligan NC, Vasilyev NV, Yoganathan AP. In vitro characterization of bicuspid aortic valve hemodynamics using particle image velocimetry. Ann Biomed Eng. 2012;40:1760-75.

10. Hope MD, Hope TA, Meadows AK, Ordovas KG, Urbania TH, Alley MT, et al. Bicuspid aortic valve: four-dimensional MR evaluation of ascending aortic systolic flow patterns. Radiology. 2010;255:53-61.

11. Della Corte A, Bancone C, Conti CA, Votta E, Redaelli A, del Viscovo L, et al. Restricted cusp motion in right-left type of bicuspid aortic valves: a new risk marker for aortopathy. J Thorac Cardiovasc Surg. 2012;144:360-9.

12. Russo CF, Cannata A, Lanfranconi M, Vitali E, Garatti A. Is aortic wall degeneration related to bicuspid aortic valve anatomy in patients with valvular disease? J Thorac Cardiovasc Surg. 2008;136:937-42.

13. Schaefer BM, Lewin MB, Stout KK, Gill E, Prueitt A, Byers PH, et al. The bicuspid aortic valve: an integrated phenotypic classification of leaflet morphology and aortic root shape. Heart. 2008;94:1634-8.

14. Tadros TM, Klein MD, Shapira OM. Ascending aortic dilatation associated with bicuspid aortic valve: pathophysiology, molecular biology and clinical implications. Circulation. 2009;119:880-90.
15. Edwards WD, Leaf DS, Edwards JE. Dissecting aortic aneurysm associated with congenital bicuspid aortic valve. Circulation. 1978;57:1022-5.

16. Roberts CS, Roberts WC. Dissection of the aorta associated with congenital malformation of the aortic valve. J Am Coll Cardiol. 1991;17:712-6.

17. Keane MG, Wiegers SE, Plappert T, Pochettino A, Bavaria JE, Sutton MG. Bicuspid aortic valves are associated with aortic dilatation out of proportion to coexistent valvular lesions. Circulation. 2000;102:III35-9.

18. Robicsek F, Thubrikar MJ, Cook JW, Fowler B. The congenitally bicuspid aortic valve: how does it function? Why does it fail? Ann Thorac Surg. 2004;77:177-85.

19. Della Corte A, Quarto C, Bancone C, Castaldo C, Di Meglio F, Nurzynska D, et al. Spatiotemporal patterns of smooth muscle cell changes in ascending aortic dilatation with bicuspid and tricuspid aortic valve stenosis: focus on cell-matrix signaling. J Thorac Cardiovasc Surg. 2008;135:8-18.

20. Girdauskas E, Borger MA, Secknus MA, Girdauskas G, Kuntze T. Is aortopathy in bicuspid aortic valve disease a congenital defect or a result of abnormal hemodynamics? A critical reappraisal of a one-sided argument. Eur J Cardiothorac Surg. 2011;39:809-14.

21. Borger MA, Preston M, Ivanov J, Fedak PW, Davierwala P, Armstrong S, et al. Should the ascending aorta be replaced more frequently in patients with bicuspid aortic valve disease? J Thorac Cardiovasc Surg. 2004;128:677-83.

22. Goland S, Szer LS, De Robertis MA, Mirocha J, Kass RM, Fontana GP, et al. Risk factors associated with reoperation and mortality in 252 patients after aortic valve replacement for congenitally bicuspid aortic valve disease. Ann Thorac Surg. 2007;83:931-7

23. McKellar SH, Michelena HI, Li Z, Schaff HV, Sundt TM 3rd. Long-term risk of aortic events following aortic valve replacement in patients with bicuspid aortic valves. Am J Cardiol. 2010;106:1626-33.

24. Andrus BW, O'Rourke DJ, Dacey LJ, Palac RT. Stability of ascending aortic dilatation following aortic valve replacement. Circulation. 2003;108:II-295-9.

25. La Canna G, Ficarra E, Tsagalau E, Nardi M, Morandini A, Chieffo A, et al. Progression rate of ascending aortic dilation in patients with normally functioning bicuspid and tricuspid aortic valves. Am J Cardiol. 2006;98:249-53.

26. Davies RR, Kaple RK, Mandapati D, Gallo A, Botta DM, Elefteriades JA. Natural history of ascending aortic aneurysms in the setting of an unreplaced bicuspid aortic valve. Ann Thorac Surg. 2007;83:1338-44.

27. Kuralay E, Demirkilic U, Özal E, Öz BS, Cingöz F, Günay C, et al. Surgical approach to ascending aorta in bicuspid aortic valve. J Card Surg. 2003;18: 173-80. 